\title{
VARIABLES DOMÉSTICAS EN LA POLÍTICA EXTERIOR DE PARAGUAY*
}

\author{
DOMESTIC VARIABLES IN THE FOREIGN POLICY \\ OF PARAGUAY
}

\begin{abstract}
Máximo Quitral Rojas**
El presente trabajo tiene como objetivo constatar si algunas variables domésticas de tipo político económico, cultural, social e ideológico, presentes en la estructura política de Paraguay, han entorpecido el desarrollo de su política exterior. Desde una perspectiva metodológica, usamos el estudio de caso, la teoría fundamentada y la investigación documental, que combina la revisión bibliográfica de textos académicos, memorias e informes estadísticos. Como conclusión se establece que estas variables domésticas se consolidaron durante la dictadura cívico-militar, y condicionaron la modernización y profesionalización del ejercicio diplomático, como también la política exterior de Paraguay.

Palabras claves: Autoritarismo, conservadurismo, burocracia (Thesaurus), clientelismo (Autor), política exterior.

The main objective of this paper is to determine if domestic political, economic, cultural, social and ideological variables present in Paraguay's political structure have hindered the development of its foreign policy. From a methodological perspective, we use the case study, the grounded theory, and the documentary methodology that combines the bibliographical review of traditional academic texts together with the analysis of academic journals. In conclusion, it was established that these domestic variables were consolidated during the civic-military dictatorship, and conditioned the modernization and professionalization of diplomatic exercise, as well as external politics.
\end{abstract}

Key words : Authoritarianism, conservatism, patronage, bureaucracy (Thesaurus), foreign policy.

\section{Introducción}

Este trabajo señala que la política exterior desarrollada por Paraguay está condicionada por variables domésticas presentes desde la época stronista ${ }^{1}$, las que han sufrido variaciones menores desde el retorno a la democracia en 1989. Es decir, "Paraguay todavía acarrea resabios autoritarios enquistados en estructuras políticas, sociales, económicas y culturales. La política exterior todavía tiene muchos elementos de este tipo de régimen que la determinan" (Insaurralde, 2014: 152). Siguiendo esta idea, el objetivo de este trabajo apunta a constatar si algunas variables domésticas presentes en la estructura política de Paraguay, como el stronismo, las posiciones conservadoras, la economía y el clientelismo, han entorpecido el desarrollo de su política exterior.
Este trabajo entiende por clientelismo como aquellas relaciones informales de intercambio recíproco y mutuamente benéfico de favores entre dos sujetos, basadas en una amistad instrumental, con diferencias de poder y control de recursos (Audelo, 2004). En el caso del stronismo, lo definimos como una visión ideológica autoritaria dominante mezclada con elementos democráticos insertas en la cultura política paraguaya. Como posiciones conservadoras, nos referimos a la conducta política asumida por la dirigencia política, que buscó mantener presente la visión stronista, evitando transformar la estructura política, social, económica e ideológica instalada durante la dictadura cívico militar. Se entienden por variables domésticas, los factores políticos, económicos, culturales, sociales e ideológicos que inciden (positiva o negativamente) la política exterior de los

\footnotetext{
* Este artículo corresponde al Proyecto de investigación de Fondecyt Chile № 1130380 titulado "El pensamiento latinoamericano en asuntos regionales y mundiales, 2002-2012" de la Universidad Arturo Prat y contó con financiamiento para el proceso de entrevistas.

** Universidad Tecnológica Metropolitana, Departamento de Economía. Santiago, Chile. Correo electrónico: maximo.quitral@utem.cl, maximoquitral@gmail.com
} 
países. En relación con la política exterior, esta se define como la relación que se construye entre un Estado con otros actores estatales en el escenario internacional, como espacio primario, aun cuando no es el único lugar donde pueden interactuar.

Bien lo señaló Parker (2004) al sostener que "La política exterior puede ser definida como una política de Estado que define las relaciones y acciones que dicho Estado se propone desarrollar en el plano de sus relaciones interestatales internacionales" (Parker, 2004: 149). Para el caso acá estudiado se considera que sí hubo una proyección de la política interna en la política exterior de Paraguay, que desde la teoría de las relaciones internacionales, y puntualmente, desde el realismo; la política interna carecería de herramientas analíticas proyectables en el escenario internacional, impidiendo establecer algún grado de coherencia entre lo interno y lo externo. Es decir, para el realismo, la diferencia entre la política interna y la política externa radica en que "mientras los determinantes de la política doméstica dependen del sistema político nacional, incluyendo la opinión pública, partidos políticos y grupos de interés, la política externa es un producto del Estado" (Lasagna, 1996: 45). De todas formas, esta mirada teórica de las relaciones internacionales propuesta por Lasagna presenta alguna inconsistencia en su explicación, ya que dejaría de lado la formulación de ideas provenientes desde otras instituciones gubernamentales, como el Parlamento u organismos no estatales que ejercen algún tipo de influencia en la opinión pública (González et al., 2018). Es decir, al producirse algún grado de inestabilidad interna de un régimen de gobierno, las probabilidades que modifique su política exterior, los objetivos de inserción internacional, los mecanismos de conexión multilateral, o simplemente, la forma de ejercer diplomacia, aumentan considerablemente. Entonces, desligar la política interna y la historia de los Estados implicaría generar cierta desconexión en la toma de decisiones de un gobierno, situación que provocaría la elevación de las asimetrías internacionales entre los Estados y debilitaría el protagonismo internacional de un país determinado (Cavieres, 2013).

Continuando con el debate respecto de política exterior, Nohlen y Fernández (1991) conciben la política exterior "como policy, cuyos resultados se ven afectados producto de los cambios introducidos por el sistema político" (Nohlen y Fernández, 1991: 230). Se puede argumentar entonces que las características internas que moldean a los Estados, como la población, la fisonomía territorial, su desarrollo económico o la capacidad militar, cohíben o estimulan el actuar internacional que desarrolla un Estado en particular. Es decir, aquella "dimensión que atiende más bien a los aspectos administrativos del poder es la que determina el comportamiento externo de un Estado y, en el ámbito estratégico-militar, el modo en que percibe las amenazas" (Calderón, 2014: 68-69). Postura similar es la que plantea Robert Putnam, para quien es prácticamente imposible separar lo interno de lo externo, asumiendo que algunos intereses domésticos de los gobiernos nacionales se tornan compatibles con la política internacional (Putnam, 1988). En esta misma dirección tomamos en consideración los aportes del realismo neoclásico, especialmente de la figura de Schweller, quien argumenta que la conformación del Estado y su estructura administrativa, moldean e influyen en el actuar internacional de las naciones. En otros términos, esta noción que atiende a elementos administrativos de los Estados son los que definirían su comportamiento internacional y el modo en que se desenvuelve externamente (Schweller, 2006).

En concordancia con nuevos enfoques teóricos que incorporan las variables internas para explicar la política exterior, como por ejemplo el liberalismo utilitario, esta corriente de pensamiento busca entender internamente el comportamiento de los Estados en su ámbito internacional (Rittberger, 2004). Agregamos en esta dirección los aportes producidos por el institucionalismo neoliberal de Keohane y Nye (1988), teoría que considera relevante los factores nacionales para entender el desenvolvimiento del Estado en cuanto a su política exterior. Finalmente, hay que destacar el aporte de Helen Ingram y Suzanne Fiederlein (1988) en la comprensión de la influencia de las variables domésticas acerca de la política exterior, otorgándoles un rol sobresaliente en la visión construida por los Estados y su proyección internacional.

Atendiendo el debate antes mencionado, es posible sostener que es impensado separar la política interna de la política externa, entendiendo que, de esta relación pendular, siempre hay elementos de la política doméstica que alcanzan una proyección central a la hora de construir una relación política como parte de una estrategia 
internacional. Por tanto, intentar construir una política internacional aislada de los intereses presentes es prácticamente imposible, porque la percepción política del Presidente no es la única relevante, salvo que esta sea liderada por un gobierno de facto. Desatenderse de esa situación provocaría descoordinación, reforzaría las asimetrías entre política interna y externa y provocaría un desbalance político que debilitaría el ejercicio político del Presidente en materia internacional (González et al., 2016). Además, esto tendría impacto en algunas esferas del Estado de proyección internacional (cancillería y diplomacia), pues al no existir una relación directa entre los objetivos internos y los externos, la política exterior sucumbe en la esfera internacional. En la praxis política y diplomática aparece cada vez más claro el hecho de que separar ambas esferas puede conducir a graves errores que operan en desmedro del interés y de la seguridad nacional (Pardo y Toklatian, 1987). Para evitar la distorsión entre la política interna y externa, lo prudente es comprender que es prácticamente imposible pensar una diplomacia autónoma de la política interna, sosteniendo en este caso que las variables internas (culturales, sociales, económicas políticas e ideológicas) son importantes en el desarrollo de la propia política internacional.

En razón de estas ideas, este trabajo se focalizó en el análisis de la política exterior de Paraguay, dividiendo el estudio en tres partes. En la primera se observan la condición interna de Paraguay y el peso de la tradición autoritaria en su estructura política. Luego se hace un recorrido histórico por la dictadura cívico-militar, el gobierno democrático de Nicolás Duarte, y se termina el análisis con el gobierno de Fernando Lugo. Finalmente, se entrega una conclusión que da cuenta de las principales ideas advertidas en este trabajo.

La hipótesis que sostiene este trabajo señala que la extensa prolongación de la dictadura militar paraguaya contribuyó a configurar una política exterior altamente ideologizada, poco pragmática, y con un cuerpo diplomático inexperto, cuya acción diplomática frena la inserción internacional y retrasa su vinculación regional y mundial. Como metodología, el presente trabajo fue elaborado sobre la perspectiva del estudio de caso para conocer en mayor detalle las particularidades y la complejidad que despliega un caso particular. Si bien el estudio de caso ha generado algunos debates en torno a su real aporte a la investigación científica (Stoecker, 1991; Reyes y Hernández, 2008), creemos que, si son seleccionados cuidadosamente, los estudios de casos pueden aportar información valiosa acerca de un tema desconocido y contribuir en la generación de nuevas interpretaciones teóricas (Chetty, 1996).

Junto con eso ocupamos la metodológica documental que enriquecieron al análisis teórico y empírico de este trabajo y aplicamos la teoría fundamentada (grounded theory), cuya característica es que, por medio de la inducción, propone una nueva conceptualización teórica de un determinado fenómeno o un conjunto integrado de hipótesis conceptuales (Glaser, 1992; Corbin y Strauss, 2002). La teoría fundadamentada permite focalizar la recolección de datos y aportar en la construcción de teorías a partir de la extracción de datos, analizando por medio de procedimientos analíticos la relación existente entre ellos. Además, se realizaron algunas entrevistas semiestructuradas a políticos y académicos relevantes del Paraguay, los que han escrito de la realidad política paraguaya y que participaron estrechamente del gobierno de Fernando Lugo.

Los entrevistados fueron definidos en función de criterios teóricos con la utilización de la técnica de la bola de nieve (Bogdan y Taylor, 1987), que consiste en acceder a los informantes por medio de contactos claves previamente ubicados, lo que permite ampliar los sujetos por medio de contactos facilitados por otras personas. Todos los entrevistados prefirieron mantenerse en el anonimato. Es preciso mencionar que existe una escasa producción académica paraguaya de la temática propuesta, comprendiendo que las ideas señaladas en este trabajo, suplen -en parte- esta debilidad, convirtiendo a este trabajo en un aporte para el estudio de las relaciones internacionales del Paraguay.

\section{Política interna y externa en el caso paraguayo}

La realidad interna de Paraguay continúa asociada a problemáticas vinculadas a los llamados Estados subdesarrollados, sobre todo en lo que concierne a la consolidación de su régimen democrático. Producto de la larga experiencia autoritaria, la política exterior paraguaya sigue estando condicionada por variables de política 
interna, la que hasta hoy no ha alcanzado una maduración central. Es decir, como señala Merlo et al.

"La larga duración de más de tres décadas del régimen militar es explicada por varios académicos haciendo referencia a la llamada unidad granítica del partido político gobernante (Partido Colorado), los militares y el Estado. Según este relato, la transición democrática desde la década de 1990 no ha sido capaz de disolver completamente la unidad granítica y las conexiones ilegítimas entre los diferentes poderes" (Merlo et al., 2014: 141)

Si bien se avanzó en terminar con los resabios desarrollados en dictadura, la realidad es totalmente opuesta. Paraguay reafirmó estos elementos que dieron forma a su aparato estatal, pues fueron el mecanismo que tuvieron las élites para cimentar su poder, basadas mayoritariamente en el clientelismo, las que se ramificaron internamente, pero que alcanzaron proyección internacional.

"O sea, esa es la cultura que el Partido Colorado instaló en este país durante sesenta años de gobierno, de los cuales 35 fueron una dictadura, liderada por el general Stroessner y sostenida por el Partido Colorado y las Fuerzas Armadas. En la democracia durante los 10 años que gobernó de la caída de Stroessner, sigue nutriendo las mismas prácticas corruptas" (Merlo y Castiglioni, 2014: 141).

Las prácticas clientelares sirvieron para obtener cargos de poder, al margen del conocimiento, la meritocracia y la trayectoria política. Si bien:

La democratización y continuismo colorado (1989-2008), etapa posterior a la caída de la dictadura de Stroessner, puede identificarse como un período de democratización del país (aspecto positivo), acompañada del continuismo colorado (aspecto negativo). Paraguay siguió por 19 años más en manos de gobernantes colorados y de empresarios afines a este partido (Ubaldi, 2009: 1).
Esta condición se tradujo en que las bases estructurales del stronismo no fueran del todo desplazadas de la política paraguaya, enquistándose fuertemente en su arquitectura democrática. A juicio de Mora (2001), ello se explica porque:

(...) la larga tradición de personalismo y reglas autocráticas en Paraguay, a partir del régimen patrimonialista de Alfredo Stroessner, se enfatizó en el rol del liderazgo del ejecutivo por sobre la legislatura y la sociedad en el proceso de toma de decisiones. La diferencia más importante entre el régimen autoritario y el régimen democrático es que bajo el primero, la política exterior estaba diseñada solo para y por el dictador, mientras que en el último, si hay una ausencia de un ejecutivo decisivo y respetado" (Mora citado en Arce, 2011: 109).

Esta misma situación también es observada por Tini (2005), quien argumenta en esta dirección que:

“(...) el cambio de régimen político de 1989 operó como una condición necesaria para lograr la reinserción internacional del país. Pero faltó la condición suficiente de una adecuada política exterior y de una diplomacia profesional y capacitada, y la imprescindible autonomía respecto de las asfixiantes y determinantes coyunturas de la política interna, para convertir al influyente factor externo en un instrumento fundamental al servicio de sus intereses nacionales" (Tini, 2005: 5-6).

Se desprende de lo anterior que las variables internas explicadas al comienzo del estudio asociadas a la influencia del stronismo y al clientelismo, han distorsionado el correcto manejo de la política exterior de Paraguay. Es decir, lo ideológico supera al pragmatismo ${ }^{2}$ como variable dominante en la política exterior de Paraguay, aunque no es lo único que ha influido en el desarrollo en su política exterior. El factor económico también resultó relevante para este país, ya que al continuar existiendo un desequilibrio económico, dichas variables impactaron en su estabilidad y 
debilitaron el actuar del Estado en la proyección de sus objetivos internacionales:

Durante la última década, la economía paraguaya creció a un promedio del 5\%, un crecimiento más alto que el de sus vecinos, aunque muy volátil. El ingreso de la parte inferior del $40 \%$ se incrementó en un $8 \%$ anual entre 2009 y 2014 y la proporción de paraguayos que viven con menos de US $\$ 4,0$ al día (umbral regional de pobreza) bajó del 32,5\% al 18,8\%. Sin embargo, la pobreza y la desigualdad de ingresos siguen siendo un reto importante (Banco Mundial, 2016).

En razón de estas condiciones internas, pero apuntando al plano económico, Paraguay tomó la decisión en 2013 de desplegar un Plan Nacional de Desarrollo (2014-2030) para reducir las desigualdades, sustentado en tres pilares: 1) reducción de la pobreza y desarrollo social; 2) crecimiento económico inclusivo, e 3) inclusión de Paraguay en los mercados globales. El primero contempló un desarrollo social equitativo, servicios sociales de calidad, desarrollo local participativo y un hábitat adecuado y sostenible. El segundo punto busca resolver, mediante el logro de empleo y mayor seguridad social, competitividad e innovación, regionalización y diversificación productiva, y, finalmente, una valoración del capital ambiental.

En lo que respecta a la inclusión de Paraguay en los mercados globales, esta categoría responde a una negativa evaluación de cómo el país se ha relacionado en el mundo y una abierta crítica a la arquitectura institucional dominante desarrollada por el stronismo. Su visión económica se determinó en razón de las prioridades de una élite económica cercana al régimen dictatorial, la que impidió cualquier transformación estructural, pues su modificación alteraría sus fuentes de acumulación y de crecimiento económico personal (Masi, 2006; Rojas, 2011). Al punto tres se suman la integración económica regional y la sostenibilidad del hábitat global, siendo este pilar clave para intentar minimizar los efectos políticos producidos por la inestabilidad democrática, la desigualdad y la corrupción en la conducción de la política externa del país.

Dicho plan estuvo fuertemente vehiculizado por las problemáticas internas que aquejaban al país, y que entorpecieron su desarrollo, no solo como reflejo de una inexperiencia diplomática o como consecuencia de la permanencia de elementos ideológicos stronistas en la proyección de su política exterior, sino también por la debilidad de su economía, que estaba cimentada en la monoexportación con escaso valor agregado. Esto ha desgastado su posición internacional y mermado su rol en espacios multilaterales, ya que, al no contar con una economía competitiva, sus productos y estrategias de vinculación internacional se redujeron a escala global. Por lo demás, los procesos electorales no han modificado en la base la relación social, la profundización de la desigualdad social y el desarrollo de los conflictos constituyen hoy las dificultades para continuar sosteniendo una democracia representativa (Peralta y Perrotta (2003).

En resumen, en Paraguay ha existido una estructura política heredada de la dictadura, donde han primado el clientelismo y la escasa profesionalización diplomática -incluso apoyada en partidos políticos que adoptaron esas formas como mecanismo de relación política-, al punto que cualquier intento por provocar algún cambio en la herencia autoritaria, no solo ha generado resistencia, sino que también desinterés por esa área de la política pública.

\section{La influencia del stronismo en la política exterior de Paraguay}

Resulta imposible comprender la actividad internacional desplegada por Paraguay durante la segunda mitad del siglo XX sin revisar la arquitectura política desarrollada por la dictadura cívico-militar de Alfredo Stroessner (1954-1989). La actual construcción institucional y la conformación de las estructuras partidarias paraguayas son el espejo de un sistema político pétreo dominado por el Partido Colorado. Ese predominio tuvo una leve interrupción tras el ascenso al poder de Fernando Lugo (2008-2012), hito político que se analizará más adelante. El poder político de los colorados se caracterizó por la represión, la corrupción, el "clientelismo, el enriquecimiento de unos pocos, el freno a la libertad de expresión, una cultura política prácticamente inexistente y una legitimidad disfrazada con procesos democráticos falsos" (Ubaldi, 2009: 1). Esto redundó en que el Estado paraguayo controlara las acciones insertas 
en el plano político interno, realidad que contribuyó a sostener el aparato burocrático militar y a fortalecer los lazos con el strosnismo. El resultado fue que la dictadura de Stroessner se estructuró bajo la coordinación de tres instituciones: a) el Partido Colorado, b) las Fuerzas Armadas y c) el Estado.

Fue así como los colorados insertos en el aparato estatal pudieron ahondar su influencia en la toma de decisiones de la dictadura, al punto que, en esa época, dicho partido logró control político y social dentro la sociedad civil. A pesar de ese nivel de control y dominación, la política paraguaya siguió estando conducida por el stronismo, lo que marcó el rumbo de la forma de actuar en el escenario internacional. Si en toda política internacional hay un poco de las condiciones humanas de sus autores, en el Paraguay, debido a la gran concentración de poder personal que fue acumulando a lo largo de treinta y cuatro años, esto adquirió ribetes increíbles (Fernández, 1991: 42) En definitiva, la política exterior paraguaya se aferró a los esquemas realistas de las relaciones internacionales y comulgó plenamente con los argumentos cristalizados en plena Guerra Fría, al punto de plantear -sin ambigüedades- que los procesos de democratización que se estaban gestando en América del Sur resultaban peligrosos y había que contenerlos. Esta actitud le significó a la dictadura de Stroessner el apoyo desde Estados Unidos, así como la protección requerida para continuar con el proyecto autoritario.

El sentido del anticomunismo explicitado de manera permanente por la dictadura cívico militar paraguaya se transformó en una característica importante, que sirvió para justificar la toma de posiciones y avalar su forma de inserción internacional. El resultado de todo esto fue que, en este período, la política exterior de Paraguay se orientó bajo los preceptos de la Guerra Fría, lo que se tradujo en un aislamiento internacional muy propio de las dictaduras sudamericanas, situación que no sufrió cambios con el retorno de la democracia.

\section{Nicanor Duarte Frutos y su política exterior (2003-2008)}

El golpe de Estado que derrocó a Stroessner en 1989, perpetrado por su consuegro, Andrés Rodríguez, dejó al descubierto un largo proceso de descomposición de la institucionalidad paraguaya, la que se vio cooptada por autoridades políticas autoritarias y conservadoras, que utilizaron al Estado para beneficio propio ${ }^{3}$. Si bien durante este período se puso fin a la dictadura y comenzó en Paraguay el llamado proceso de transición a la democracia, lo que en realidad se produjo fue solo un cambio de régimen más, pero no una profunda transformación del conjunto del Estado. Si bien el gobierno de Nicanor Duarte fue relativamente exitoso en su gestión, existieron ciertas inconsistencias en la aplicación de una política exterior más bien oscilante. Esto se explica porque el gobierno de Duarte se acercó al Mercado Común del Sur (en adelante Mercosur) y a Estados Unidos, con el objetivo de establecer acercamientos con Brasil y abrir nuevas opciones de negociones con empresas hidroeléctricas.

Este acercamiento respondió a la construcción de una política exterior más bien autónoma y con un enfoque centrado en la integración regional, apelando a que esa nueva diplomacia se elaboraría a base de una matriz cultural propia. Es decir, el enfoque dado por esta administración fue reinstalar al Paraguay en el concierto internacional e intentar distanciarse de posiciones stronistas predominantes en la política exterior de Paraguay. En el caso de Estados Unidos, se buscó aumentar la cooperación entre las dos naciones, se profundizaron los ejercicios militares y se aumentó la presencia de efectivos norteamericanos en el país, al punto de autorizar la instalación de una oficina del FBI. Pese a los esfuerzos del Presidente por consolidar una política exterior más autónoma, nuevamente las variables internas (como la economía) continuaron impactando en su vinculación internacional.

Al ser la economía paraguaya "poco competitiva, con fuerte peso del sector campesino arcaico, cuartomundista, con un empresariado poco homogéneo y nada moderno, con instituciones estatales y sociales de baja intensidad, dicha realidad frenó los intentos por hacer de Paraguay un país moderno y competitivo internacionalmente (Rodríguez, 2006). Fue así como en 2006 el diario ABC Color, señaló que Paraguay entró en severa crisis socioeconómica, la que no solo amenazó al país con el colapso económico y la ruptura política y el conflicto social, que debilitó la idea de generar un Paraguay estable y pujante.

La crisis económica que tuvo que enfrentar Duarte sembró incertidumbre sobre el plan de 
recomposición sociopolítico propuesto por su gobierno, porque el Estado estaba prácticamente quebrado, con un PIB negativo para 2003, producto de un "largo estancamiento económico y las crisis financieras sucesivas entre 1995 y 2002 (Flecha, 2012). A esto se debe agregar la caída en los precios internacionales del algodón y la soya, que provocaron una gran contracción de la economía que puso de manifiesto el agotamiento del modelo productivo agrario con sus secuelas de desempleo, migraciones, y crecimiento sostenido de la economía informal (De Riz, 2007). Si bien el ex-Presidente Duarte delineó en algún momento una posición diferente de lo que había hecho tradicionalmente Paraguay con Estados Unidos, esta orientación fue más bien moderada. Por ejemplo, en 2007, Duarte señaló al diario $A B C$ :

América Latina está preocupada por otros problemas como la falta de inversiones y la lucha contra la pobreza. La región ya no está expectante de lo que haga o piense Estados Unidos y tiene su propia política [...] Hay un nuevo eje de poder en América Latina [...] una nueva visión de lo que debe ser el protagonismo de nuestra región en el mundo, en la política, la economía y la búsqueda de la paz (ABC, 2007).

Pero no fueron solo esos problemas los que debió enfrentar el Presidente. En materia de política exterior, Duarte se encontró con un país que tuvo que enfocarse más en las crisis políticas internas que en la idea de la reinserción internacional del Paraguay, por tres razones:

"La falta de legitimidad política de esos gobiernos ${ }^{4}$ y el escaso apoyo de la estructura partidaria oficialista a los mismos, que además provoca constantes inestabilidades; una crisis económico-financiera que lleva al país a la recesión y a múltiples protestas sociales, haciendo que los gobiernos trabajen casi exclusivamente sobre los problemas internos; y una falta creciente de interés tanto de la sociedad civil como del Poder Legislativo sobre el tema internacional" (Arce, 2011: 111).
Si bien estos factores son importantes, la falta de profesionalismo dentro del cuerpo diplomático (variable interna de tipo político) inhibió la capacidad de inserción de Paraguay y su presencia internacional.
“(...) la falta de profesionalismo, mo- dernización y racionalización es un elemento de la política exterior que aca- rrea todavía como legado autoritario. Como consecuencia, la política exterior paraguaya no logra adaptarse a las nuevas realidades que el sistema internacional le impone y no establece ni deduce una agenda coherente de temas prioritarios. Esto se ve coadyuvado por las constantes crisis políticas acaecidas en el país, que se reproducen en el seno del ministerio" (Insaurralde, 2014: 152).

Como la relación de Nicanor Duarte con los países miembros de Mercosur fue más bien ambigua y oscilante, este actuar fue un obstáculo para lograr reposicionar a Paraguay en el escenario regional y mundial. Además, tampoco era representante de un sector empresarial, como sí lo fueron Juan Carlos Wasmosy (1993-1998) o Raúl Cubas (1998-1999), restándole el apoyo de una élite económica local. Nicanor Duarte encarnó la renovación de la política, con un ministro de Hacienda independiente (Dionisio Borda), para quien el redireccionamiento de la economía fue uno de los principales objetivos de su administración. Es decir, al asumir su gobierno, la situación de Paraguay era delicada y con un inminente colapso económico, siendo la preocupación mayor del Presidente de cohesionar internamente al país, más que transformar a Paraguay en un actor influyente. Nuevamente, las variables internas contuvieron el avance del país en materia internacional. Uno de los entrevistados para esta investigación señaló que:

"La política exterior paraguaya entre el 2005 y 2013 fue tan cambiante, como cambiaron los gobiernos. Nicanor Duarte Frutos, sin lugar a dudas exponente del ala más progresista del Partido Colorado, se adaptó a la tendencia regional y, así, acompañó el "no al ALCA", la creación de la CELAC y, en general, propuestas 
de los países con gobiernos progresistas en la región. Internamente sucumbió a los intereses de los agroexportadores y latifundistas, sojeros y ganaderos. Ello le llevó a un cierto distanciamiento de las políticas externas más progresistas en la última parte de su mandato" (Alcides, comunicación personal, 2014).

A pesar de todas las dificultades que debió resolver el gobierno de Duarte, de todas formas incorporó ideas de su política interna que repercutieron en su política externa. Asumió que era importante mirar hacia el Atlántico para reducir el poder de Brasil y Argentina, en un espacio regional dominado por esos dos países. En esta visión del espacio regional, Nicanor Duarte incorporó a actores de la sociedad civil históricamente desplazados del debate diplomático público (puntualmente las organizaciones sociales) para que entregaran su mirada respecto del concepto de soberanía. Esta novedosa idea en el diseño de la política exterior se conjugó con el otorgamiento de una mayor autonomía al país respecto de los poderes regionales tradicionales, como Brasil y Argentina, con el interés de obtener una mayor capacidad negociadora en los distintos foros internacionales en los que participó.

Para que esto se concretara, resultó importante avanzar en la eliminación del diseño político estructural heredado de la dictadura, descomprimir la mirada conservadora de la política exterior y profesionalizar el cuerpo diplomático. Aunque se progresó en materias relevantes como autonomía política frente a las potencias regionales y una mayor cooperación política con países de la región, quedaron temas pendientes como la inserción de los productos paraguayos en el mercado internacional y la atracción de capitales extranjeros.

\section{Fernando Lugo y la reorientación internacional de Paraguay (2008-2012)}

Con el ascenso al poder de Fernando Lugo (2008-2012), la política exterior tomó un curso distinto en su orientación, ya que se insistió en reforzar las relaciones con los países vecinos, al igual que lo acontecido con el anterior gobierno, y se enfatizó en la defensa estatal de los intereses económicos de Paraguay, sobre todo sus recursos naturales. La incorporación del poder legislativo en la discusión acerca de política exterior lo transformó en un actor central para decisiones futuras en esa materia. Por ejemplo, cuando se discutió el ingreso de Venezuela al Mercosur, tal debate se tradujo en un acercamiento de la administración de Lugo a Venezuela y un ostensible distanciamiento con Estados Unidos, rompiendo Paraguay la vinculación que siempre tuvo hasta ese momento ${ }^{5}$.

Esta nueva percepción de la realidad paraguaya en el escenario internacional se fue extendiendo en el tiempo con el ascenso al poder de Fernando Lugo, quien mantuvo la independencia sostenida por Duarte respecto de Estados Unidos, al punto de rechazar una base militar de ese país en suelo paraguayo. Como el ex-Presidente era representante de un sector más progresista del Partido Colorado, esta tendencia de posición más bien autonomista fue continuada con Lugo, a pesar de la existencia de grupos de poder conservadores que observaron con preocupación los cambios introducidos por el Presidente en ejercicio:

"Lugo apoyó y se comprometió con todas las propuestas progresistas de la región, como Unasur, el Banco del Sur y la CELAC. Al inicio del mandato la línea fue más conservadora, con muy buenas relaciones con los EE.UU, lo que se fue deteriorando ante diversos incidentes (destitución de Bareiro Spaini; salida del gobierno del sector más conservador, que influyó en las relaciones internacionales, como Rafael Filizzola), reafirmándose la línea más consecuentemente progresista, particularmente desde la designación de Jorge Lara Castro como Canciller" (Alberto, comunicación personal, 2014).

La explicación del entrevistado dos acerca de este giro hecho por Lugo -que pasó de una posición contenida o moderada a otra más progresista y cercana a los gobiernos de izquierda surgidos en la región- se debió al acercamiento con Venezuela. Esta conexión política provocó una tensión regional cuando se discutió el ingreso de Venezuela al Mercosur. Si bien Lugo se mostró partidario de acercarse con Venezuela y profesionalizar el ejercicio diplomático: 
"El breve gobierno de la alternancia (2008/12) mostró una actitud más abierta, pero duró poco y tampoco se logró institucionalizar /modernizar una Cancillería poco preparada técnicamente $\mathrm{y}$ bien ineficiente en el manejo de las Relaciones Internacionales RREE" (Eliecer comunicación personal 2014).

Para Gustavo Codas (2009): "En política exterior es posiblemente donde mayores avances ha logrado este gobierno. Afirma que el cambio trascendental se observa en la voluntad del gobierno de actuar como Estado soberano, frente a la política de subordinación de las administraciones coloradas" (Codas citado en Uharte, 2009). En el fondo, el presidente Lugo avanzó en romper la lógica stronista presente en la política exterior de Paraguay, con predominio de la subordinación, el autoritarismo y el clientelismo, para proponer un nuevo ciclo político donde primó la autonomía en la toma de decisiones internacionales. Es decir, esta idea del actor único, expresada en la figura autoritaria de Stroessner -con la que se desarrolló la política exterior de Paraguay, y la que fue la hoja de ruta política de ese entonces-, dio paso a una forma de acción política que buscó ampliar los vínculos internacionales, acercándose a gobiernos que intentaban obtener una mayor autonomía política, como también abrirse a la integración, pero manteniendo las formas clientelares.

Por ejemplo, el entonces Presidente "trazó una línea errática en materia de política exterior, al colocar en la Cancillería a un hombre -Hamed Franco- sin análisis geopolítico, con escasa formación en economía política y nula visión estratégica sobre la crisis sistémica mundial" (Imengri, 2015: 191). Esta situación redundó en que, una vez más, los temas internacionales no eran coordinados por expertos en el tema. A pesar de estos esfuerzos, Insaurralde sostiene que, en general, la política exterior de Paraguay se puede resumir en cuatro factores explicativos: una política exterior con ciertos resabios autoritarios, con falta de racionalidad, profesionalización y modernización del servicio diplomático. Una centralidad en el proceso de toma de decisiones y, derivado de ello, la importancia de la diplomacia presidencial para catalizar procesos relevantes en la cancillería.
Tenue "pendularidad", generada por la posición geopolítica de Paraguay pero degradada a partir de la conformación del Mercosur y la recuperación de la soberanía energética (Insaurralde, 2014).

Estos puntos exponen una política exterior que ha presentado problemas para distanciarse de una herencia autoritaria consolidada durante la dictadura cívico-militar en Paraguay, manifestada en prácticas clientelares y en el excesivo protagonismo del Presidente en esas materias. Esas variables internas se expresan en la segunda idea que razona Insaurralde, quien advierte que esta centralidad afectó la buena conducción de la diplomacia, como también debilitó el desarrollo de una política diplomática moderna acorde a como se mueve el mundo hoy. Por tanto, el establecimiento del Plan de Desarrollo apuntó justamente a transformar esa situación y a reconocer los errores del pasado y proponer una hoja de ruta que guíe a Paraguay en la senda del reconocimiento internacional y de la requerida estabilidad política. No solo se pensó en resolver la interrogante de la soberanía energética como objetivo económico superlativo sino, también, cómo ese objetivo estaría complementado con una diplomacia experta en estas materias. En relación con la recuperación de la soberanía energética, fue algo que con Duarte Frutos se exploró y que con Lugo se logró avanzar. No obstante, hubo oposición interna a esta idea, ya que con ello se pretendía estar al servicio de políticas chavistas, postura que finalmente no se pudo ejecutar en plenitud, tras la destitución del Presidente del poder. En este caso, la política interna terminó por imponer su agenda internacional.

\section{Colofón}

A lo largo de este trabajo se intentó explicar que la política exterior de Paraguay sigue manteniendo tradiciones autoritarias e ideológicas, provenientes del stronismo, variables importantes a la hora de moldear su política exterior. Si bien hay matices entre el período dictatorial y los gobiernos democráticos de Duarte Frutos y Fernando Lugo intentaron transformar el paso del stronismo en la política internacional, a la hora de hacer un balance político de este país sobre el peso de las variables domésticas provenientes del stronismo 
en su política exterior, lo cierto es que siguen estando presentes en el ejercicio diplomático paraguayo. Así como se indicó en la introducción de este trabajo, las variables domésticas presentes en los países tienen un papel fundamental a la hora de proponer su política exterior. Considerando el aporte teórico hecho por el realismo o el institucionalismo neoliberal presentado al comienzo de este estudio y su comprobación en el estudio de caso propuesto, es posible sostener que esta se expresa en la realidad política paraguaya y que gran parte de estas variables provienen de la época de la dictadura cívico miliar de Stroessner. Estas variables internas buscaron satisfacer los intereses del Estado paraguayo, como también los de una élite cercana al aparato estatal, contribuyendo a que la política exterior de Paraguay contara con una combinación de variables domésticas (como el stronismo y el clientelismo) y variables internacionales, pero advirtiendo que las primeras se terminan de imponer por sobre las segundas. Las variables domésticas han dado forma a una política exterior con alto sesgo ideológico, que la transición a la democracia y los gobiernos que la precedieron no lograron superar. Claro está, la institucionalidad quedó amarrada a esas fórmulas políticas, y eso podría ser una explicación del desinterés inicial por modificarla, sosteniendo finalmente una posición ideológica por sobre posiciones pragmáticas, dotando de rigidez a su política exterior e inhibiendo la posibilidad de adaptarse a nuevas realidades internacionales. Esto, además, alentado por un cuerpo diplomático poco profesional y escasamente preparado para instalar a Paraguay como un protagonista regional, alejado del predominio de la tradición autoritaria, ideológica, clientelar y burocrática que dominó por varios años el escenario político.

Estos factores han dificultado el desarrollo de una estrategia de posicionamiento internacional acorde a los nuevos tiempos, de acercamiento de
Paraguay con las naciones más avanzadas. Quizás el Plan Nacional de Desarrollo que se impulsa para los años 2014-2030 pueda revertir esta situación, pero, como es de aplicación reciente, sus resultados aún no son perceptibles de evaluar. El Estado paraguayo, con su fragilidad democrática, no ha podido sustentar una política exterior distanciada del stronismo, que fue sustentada por mucho tiempo por el Partido Colorado y que burocratizó su actuar internacional. Además, la política exterior paraguaya ha sido más bien reactiva en el concierto regional y mundial, sobre todo por la ausencia de un cuadro de personas que conduzca la política exterior, evidenciando así el inmovilismo diplomático que permeó la cancillería y la relevancia de la continuidad histórica autoritaria en el diseño exterior.

Estas variables domésticas, sumadas a episodios de inestabilidad política, han determinado que la política exterior de Paraguay siga siendo un tema pendiente, ya que los Presidentes en ejercicio han debido focalizar sus preocupaciones en resolver las disputas internas, antes que entrar en un proceso de modernización de su política exterior. Este es uno de los grandes desafíos que tiene la democracia en Paraguay: desprenderse de factores históricos autoritarios, burocráticos e ideológicos que condicionan esta área, así como dotar del profesionalismo necesario a su cuerpo diplomático para constituirse en un actor destacado en el escenario latinoamericano y global. Para terminar, resulta valioso ahondar en aspectos teóricos respecto de la incidencia de las variables domésticas en la proyección de la política exterior de los Estados periféricos, apuntando a establecer nuevos marcos analíticos de comprensión de la realidad política latinoamericana, que logren entender cómo esas variables internas repercuten en la generación de la política internacional de los Estados, siendo esta investigación una contribución a ese objetivo. 


\section{Referencias Citadas}

$A B C$

2006 "Los primeros dos años del gobierno de Nicanor Duarte Frutos en el contexto de la transición a la democracia". $A B C, 28$ de mayo http://www.abc.com.py/ edicion-impresa/economia/los-primeros-dos-anos-delgobierno-de-nicanor-duarte-frutos-en-el-contexto-dela-transicion-a-la-democracia-906956.html (17 de abril $A B C$ 2018).

2007 "En triple frontera no se financia el terrorismo, dice Duarte Frutos". ABC color, 24 de septiembre.

Arce, L.

2011 "En la búsqueda de una estrategia global: la política exterior del Paraguay". En Cuadernos sobre Relaciones Internacionales, Regionalismo y Desarrollo 11, pp. 105-127.

Audelo, J.

2004 “¿Qué es el clientelismo? Algunas claves para entender la política en los países en vías de consolidación democrática". Revista de Alimentación Contemporánea y Desarrollo Regional 24, pp. 124-142.

Banco Mundial

2016 Paraguay: panorama regional. 20 de abril, www. bancomundial.org/es/country/paraguay/overview (17 de abril 2019).

Bogdan, R. y Taylor, S.

1987 Introducción a los métodos cualitativos de investigación. Buenos Aires: Paidós.

Calderón, E.

2014 "Variables domésticas y política exterior: el condicionamiento del contexto interno brasileño sobre las políticas de seguridad en la frontera con Colombia". En Revista de Relaciones Internacionales 47, pp. 67-86.

Cavieres, E.

2013 "Región y Nación. Relaciones vecinales, historia y nación. Desafíos pendientes y tareas inconclusas", en Revista Diálogo Andino 42, Universidad de Tarapacá, pp. 31-40.

Comisión Económica para América Latina y el Caribe

2014 Panorama Social de América Latina 2014. Santiago: Cepal.

Corbin, J. y Strauss, A.

2002 Bases de la investigación cualitativa. Técnicas y procedimientos para desarrollar la teoría fundamentada. Antioquia: Editorial Universitaria de Antioquia.

Chetty, S.

1996 "The Case Study Method for Research in Small-and Medium-Sized Firms". En International Small Business Journal 1, pp. 73-85.

De Riz, L.

2007 Los dilemas de la democracia paraguaya. Ponencia presentada en el Seminario de cultura política y alternancia en América Latina, Madrid, España.

Fernández, J.

1991 "Perspectivas de cambio de la política exterior paraguaya". En Revista Estudios Internacionales 24, pp. 42-52.

Flecha, V.

2012 Breve historia del Paraguay, 1811-2011. Asunción: Fondec, Servilibro.
Imengri, J.

2015 "Paraguay: transnacionalismo vs. Integración". En Marco Gandásegui, Carlos Martins y Pablo Vommaro, ed., Soberanía, hegemonía e integración. Quito: IAEN.

González et al.

2016 "La cuestión del río Lauca desde la perspectiva multiescalar: ¿un juego de suma de las diplomacias boliviana y chilena". En Revista Diálogo Andino 51. Universidad de Tarapacá, pp. 57-72.

González et al.

2018 "El papel de la paradiplomacia entre el norte de Chile y el sur del Perú: antecedentes históricos, limitaciones institucionales y nuevos desafíos "posfallo de la Haya". En Revista Diálogo Andino 55, pp. 79-91.

Glaser, B.

1992 Basics of Grounded Theory Analysis. Emergence vs Forcing Basics of Grounded Theory Analysis. California: Sociology Press.

Ingram, H. y Fiederlein, S.

1988 Traversing boundaries: a public policy approach to the analysis of foreign policy. En The Western Political Quarterly, 4, pp. 725-745.

Insaurralde, $\mathrm{G}$.

2014 “Oposición parlamentaria y política exterior. El rechazo del Partido Colorado al ingreso de Venezuela al Mercosur durante el gobierno de Fernando Lugo (20082012)". En Estudos Internacionais 2, pp. 149-188.

Keohane, R. y Nye, J.

1988 Poder e interdependencia: la política mundial en transición. Buenos Aires: Grupo Editorial Latinoamericano.

Lasagna, $\mathrm{M}$.

1996 "Cambio institucional y política exterior: un modelo explicativo". En Afers Internacionals 32, pp. 45-64.

Masi, F.

2006 Paraguay: los vaivenes de la política comercial externa en una economía abierta. Asunción: CADEP.

Merlo et al.

2014 Paraguay desde la perspectiva de Michel Foucault. Asunción: Sociodata.

Molinas, J.; Pérez-Liñán, A; Saiegh, S. y Montero, M.

2012 "De la concentración a la fragmentación. El juego político en Paraguay en los últimos 50 años". En Carlos Scartascini, Pablo Spiller, Ernesto Stein y Mariano Tommasi, ed., El juego político en América Latina. ¿Cómo se deciden las políticas públicas?, Bogotá: BID.

Mora, F.

1998 "The Forgotten Relationship: United States-Paraguay Relations, 1937-89”. En Journal of Contemporary History 3, pp. 451-473.

Nohlen, D. y Fernández, M.

1991 "Democratización y política exterior: análisis comparado en torno a tres casos: Argentina, Brasil y Uruguay". En Revista Estudios Internacionales 94, pp. 229-259.

Pardo, R. y Tokatlian, J.

1987 "Política Internacional, paz interna e interés nacional". Revista de Estudios Internacionales 80, pp. 435-441.

Parker, C.

2004 "Sobre política exterior iniciando el siglo XX". En Revista de Sociología 18, pp. 149-157. 
Peralta, V. y Perrotta, M.

2003 "Paraguay: contexto económico, político y social. Situación general del país". En Mauricio Torres Tovar y Natalia Paredes Hernández, ed., Derecho a la salud en países de América Latina, Washington: Alames, http:// www.bvsde.paho.org/bvsacd/cd53/dersal/cap9.pdf

Putnam, R

1988 "Diplomacy and Domestic Politics: The Logic of Two-Level Games". En The MIT Press 3, pp. 427-460.

Reyes, P. y Hernández, A.

2008 "El Estudio de Caso en el contexto de la Crisis de la Modernidad". En Revista Cinta Moebio 32, pp. 70-89.

Rittberger, V.

2004 Approaches to the Study of Foreign Policys Derivated from International Relations Theories. Tübingen: Center for International Relations/ Peace and Conflict Studies, Institute for Political Science, University of Tübingen.

Rodríguez, J.

2006 "La nueva política pendular de Paraguay: entre el Rojas, L. Mercosur y el ALCA". Nueva Sociedad 203, pp. 10-14.

2011 "Las reformas neoliberales de Primera y Segunda Generación en el Paraguay". En Luis Rojas Villagra eds., La economía paraguaya bajo el orden neoliberal. Asunción: BASE.

Ruiz, H.

2013 Golpe de Estado en el Paraguay. Un proyecto político antidemocrático y contra la integración: la seguridad democrática y la violación de las disposiciones del protocolo de USHUAIA. Asunción: Arandura Editorial Frente Guasu.

Schweller, R.

2006 Unanswered threats: Political Constraints on the Balance of Power. New Jersey: University Press.

Stoecker, R.

1991 "Evaluating and rethinking the case study". The Sociological Review 1, pp. 88-112.

Tini, $\mathrm{N}$.

2005 Las variables domésticas en la política exterior: Argentina y Paraguay. (1 de septiembre. http://www.iri. edu.ar/publicaciones_iri/IRI\%20COMPLETO $\% 20 \% 20$ Publicaciones-V05/CD-Cerpi\%202005/trabajos/Tini.pdf (25 de mayo de 2018).

Tokatlian, R. P.

1987 Política internacional, paz interna e interés nacional. En Revista Estudios Internacionales 80, pp. 435-441.

Ubaldi, C.

2009 Transición política en Paraguay. Análisis de coyuntura de los primeros meses de gobierno de Fernando Lugo. 9 de mayo, http://paraguay.sociales.uba.ar/tallerparaguay/ii-taller-2009 (18 de junio de 2018).

Uharte, L

2009 "El gobierno de Lugo: transición, cambio político y nueva ecuación democrática". Revista NOVAPOLIS 4, pp. 1991-2015.

\section{Notas}

1 La época stronista se refiere al período en que llegó al poder en Paraguay el general Alfredo Stroessner, en 1954, por vía de un golpe de Estado cívico-militar, y que terminó también con otro golpe de Estado, en 1989.

2 Se entiende por pragmatismo una política de Estado que identifica propósitos claros y metas definidas a largo plazo. En dichos propósitos existen costos y beneficios asociados a esta estrategia, los que se deben incorporar al diseño de una política exterior que se busca desplegar.

3 El caso más complejo fue el del ex-Presidente Luis Ángel González Macchi, que gobernó entre 1999 y 2003, quien fue acusado de corrupción, y además vivió un intento de golpe de Estado, que, si bien no se concretó, debilitó profundamente su gobierno. Junto con ello, en su mandato se lograron los niveles más altos de pobreza y de desigualdad social.

$4 \quad$ El autor se refiere a los gobiernos de Juan Carlos Wasmosy (1993-1998) y el de González Macchi (1999-2003).

5 Uno de los trabajos recomendables para entender el duro proceso económico experimentado por Paraguay es "De la concentración a la fragmentación. El juego político en Paraguay en los últimos 50 años" de Molinas, Pérez-Liñán, Saiegh y Montero (2012). No solo se hace énfasis en datos macroeconómicos de la administración de Duarte, sino que hay una teorización destacada acerca del rol que tuvo la dictadura de Stroessner, así como en la relación entre dos dimensiones de las políticas públicas: el eje adaptabilidad-rigidez política y la tensión entre la orientación pública o privada de las políticas. 